\title{
Identification of altered microRNAs and mRNAs in the cumulus cells of PCOS patients: miRNA-509-3p promotes oestradiol secretion by targeting MAP3K8
}

\author{
Xin Huang ${ }^{1, *}$, Chang Liu ${ }^{2,}{ }^{*}$, Cuifang Hao ${ }^{1}$, Qianqing Tang ${ }^{3}$, Riming Liu ${ }^{3}$, Shaoxia Lin ${ }^{3}$, \\ Luping Zhang ${ }^{1}$ and Wei Yan ${ }^{1}$ \\ ${ }^{1}$ Reproductive Medicine Centre, Affiliated Hospital of Qingdao Medical University, Yuhuangding Hospital of Yantai, \\ Yantai, Shandong, People's Republic of China, ${ }^{2}$ Shandong University School of Medicine, Jinan, Shandong, People's \\ Republic of China, ${ }^{3}$ Department of Laboratory, Affiliated Hospital of Qingdao Medical University, Yuhuangding \\ Hospital of Yantai, Yantai, Shandong, People's Republic of China, " (Xin Huang and Chang Liu contributed \\ equally to this work)
}

Correspondence should be addressed to X Huang; Email: huangxin92129@163.com

\begin{abstract}
Polycystic ovary syndrome (PCOS) is a common endocrine and metabolic disorder in women and is characterised by polycystic ovaries, hyperandrogenism and chronic anovulation. Although the clinical and biochemical signs of PCOS are typically heterogeneous, abnormal folliculogenesis is considered a common characteristic of PCOS. Our aim is to identify the altered miRNA and mRNA expression profiles in the cumulus cells of PCOS patients to investigate their molecular function in the aetiology and pathophysiology of PCOS. In this study, the miRNA expression profiles of the cumulus cell samples isolated from five PCOS and five control patients were determined by an miRNA microarray. At the same time, the altered mRNA profiles of the same cumulus cell samples were also identified by a cDNA microarray. From the microarray data, 17 miRNAs and 1263 mRNAs showed significantly different expression in the PCOS cumulus cells. The differentially expressed miRNA-509-3p and its potential target gene (MAP3K8) were identified from the miRNA and mRNA microarrays respectively. The expression of miRNA-509-3p was up-regulated and MAP3K8 was down-regulated in the PCOS cumulus cells. The direct interaction between miRNA-509-3p and MAP3K8 was confirmed by a luciferase activity assay in KGN cells. In addition, miRNA-509-3p mimics or inhibitor transfection tests in KGN cells further confirmed that miRNA-509-3p improved oestradiol $\left(E_{2}\right)$ secretion by inhibiting the expression of MAP3K8. These results help to characterise the pathogenesis of anovulation in PCOS, especially the regulation of $\mathrm{E}_{2}$ production.

Reproduction (2016) 151 643-655
\end{abstract}

\section{Introduction}

Polycystic ovary syndrome (PCOS) is the most common and complex endocrinopathy. It affects $6-8 \%$ of reproductive-aged women (Shi et al. 2012) and accounts for approximately $75 \%$ of anovulatory infertility (Diao et al. 2004). It is a multi-factorial and heterogeneous syndrome with variable phenotypes, including hyperandrogenism, menstrual irregularity and polycystic ovarian morphology (Group REA-SPCW 2004). In addition to infertility, patients with PCOS have an increased risk of developing metabolic disorders, such as type 2 diabetes (T2D), insulin resistance, obesity (Kandaraki et al. 2009) and cardiovascular disease (Wild et al. 2000, Carmina 2009).

Although the clinical and biochemical signs of PCOS are typically heterogeneous, abnormal folliculogenesis is considered a common characteristic of PCOS
(Fux Otta et al. 2013, Christakou \& DiamantiKandarakis 2014). In fact, there is an intrinsic difference between the polycystic ovary (PCO) and the normal ovary during the process of folliculogenesis (Franks et al. 1998). Anovulation is often induced by abnormal folliculogenesis in PCOS, which is characterised by the apparent arrest of antral follicle development at the 5-10 mm stage and, consequently, the failure to enter the preovulatory phase of the cycle (Franks et al. 1988). Although the exact pathogenesis of anovulation in PCOS is unclear, possible mechanisms have been proposed. Specifically, high levels of oestradiol in PCOS patients prevent an increase in follicle-stimulating hormone (FSH) level, which is an essential factor for follicular growth and ovulation induction. A low level of FSH consequently leads to anovulation, a major feature of PCOS (Kenigsberg et al. 2009). 
To elucidate the pathophysiology of abnormal folliculogenesis in PCOS, many genes were identified using cDNA microarrays in theca cells (Wood et al. 2004), whole ovaries (Jansen et al. 2004, Oksjoki et al. 2005), oocytes (Wood et al. 2007), cumulus cells (Kenigsberg et al. 2009, Haouzi et al. 2012) and adipose tissue (MannerasHolm et al. 2014). These studies revealed several ontologies and genes that are primarily involved in the insulin receptor signalling pathway, steroid biosynthesis and regulation of gonadotropin secretion (MohamedHussein \& Harun 2009). However, how these genes are post-transcriptionally regulated is poorly understood.

MicroRNA is a single-stranded and small noncoding RNA sequence (19-25 nucleotides in length) that negatively regulates the expression of target genes in a post-transcriptional manner, either by inhibiting translation or by degrading the target mRNA (Yates et al. 2013). It is notable that miRNAs were related to several reproductive disorders, such as endometriosis (Carletti \& Christenson 2009), poor ovarian response (Donadeu et al. 2012) and, very recently, PCOS (Carletti \& Christenson 2009, Hawkins \& Matzuk 2010, Chen et al. 2013, Hossain et al. 2013, Murri et al. 2013, Roth et al. 2014, Liu et al. 2015, Shi et al. 2015, Xu et al. 2015). Regarding PCOS, microarray profiling of human follicular fluid revealed that 29 miRNAs were differentially expressed between PCOS and fertile oocyte donors. Pathway analysis revealed that target genes were involved in insulin regulation and inflammation (Roth et al. 2014). miRNA-21, miRNA-27b, miRNA-103 and miRNA-155 were differentially expressed in the serum between PCOS and normal women (Murri et al. 2013). It has been shown that miRNAs that play important roles in the metabolic and immune system processes are influenced by obesity and circulating androgen concentrations in PCOS patients. In addition, miRNAs are involved in regulating blastocyst development. The experiment showed that morphologically similar blastocysts derived from patients with polycystic ovaries exhibited a significant decrease in the expression of six miRNAs (let-7a, miRNA-19a, miRNA-19b, miRNA-24, miRNA-92 and miRNA-93) compared with donor-fertile control blastocysts (McCallie et al. 2010).

The aim of this study is to establish the miRNA and mRNA expression profiles of the cumulus cells isolated from PCOS or control patients who were under controlled ovarian stimulation (COS) cycles using a miRNA or a cDNA microarray analysis. The molecular functions of the differentially expressed miRNAs and the predictive target genes were further investigated. The results help to characterise the pathogenesis of abnormal folliculogenesis in PCOS.

\section{Materials and methods \\ Participants}

This study was approved by the Institutional Ethics Review Board of Affiliated Hospital of Qingdao Medical University
(Yuhuangding Hospital of Yantai, Shandong, People's Republic of China). A total of 36 participants (18 PCOS and 18 controls), who referred to our centre for IVF, were included in this study after obtaining written informed consent. All of the patients had no history of drugs affecting glucose and lipid metabolism and were without any known medical conditions or diseases, including Cushing's syndrome, congenital adrenal hyperplasia, androgen-secreting tumours and endometriosis. We measured the levels of FSH, luteotrophic hormone $(\mathrm{LH})$, oestradiol $\left(\mathrm{E}_{2}\right)$, testosterone $(\mathrm{T})$ and progesterone $(\mathrm{P})$ on day 3 of the menstrual cycle before the ovarian stimulation for all of the patients by radioimmunoassay (RIA). The PCOS patients were diagnosed according to the revised Rotterdam European Society of Human Reproduction and Embryology/American Society for Reproductive Medicine Criteria (2004). The PCOS patients were required to present at least two of the following criteria: chronic oligo-ovulation or anovulation, androgen excess and polycystic ovaries. The inclusion criteria of the recruited PCOS patients in this study were as follows: age $<36$ years, body mass index (BMI) ranging between 20 and $26 \mathrm{~kg} / \mathrm{m}^{2}$, basal serum $\mathrm{LH} / \mathrm{FSH}$ levels more than $2.0 \mathrm{mlU} / \mathrm{mL}$, serum testosterone levels more than $0.5 \mathrm{ng} / \mathrm{mL}$, antral follicle count ranging between 18 and 35 and number of obtained oocytes ranging between 12 and 28 per cycle. The control patients had regular menstrual cycles, normal ovary sonographs and normal ovulating with bilateral tube occlusion; were nondiabetic; and showed no clinical signs of hyperandrogenism and anovulation. The clinical characteristics of the PCOS and control patients are summarised in Table 1.

\section{Ovarian stimulation}

Patients in both the groups received an agonist protocol as described previously (Huang et al. 2013a). Specifically, all of the patients subcutaneously received the GNRH agonist triptorelin acetate $(0.05 \mathrm{mg} /$ day, diphereline; Ipsen Pharma Biotech, Paris, France) starting at the mid-luteal phase. Once adequate pituitary down-regulation was confirmed (serum LH levels $<3.0 \mathrm{ng} / \mathrm{mL}$ and serum $\mathrm{E}_{2}$ levels $<30 \mathrm{pg} / \mathrm{mL}$ ), the patients

Table 1 Clinical characteristics of patients.

\begin{tabular}{lccc}
\hline & $\begin{array}{c}\text { Normal } \\
(n=18)\end{array}$ & $\begin{array}{c}\text { PCOS } \\
(n=18)\end{array}$ & P value \\
\hline Age $($ years $)$ & $34.6 \pm 2.2$ & $32.6 \pm 3.1$ & $\mathrm{NS}$ \\
$\mathrm{BMI}\left(\mathrm{kg} / \mathrm{m}^{2}\right)$ & $21.4 \pm 1.8$ & $21.6 \pm 1.5$ & $\mathrm{NS}$ \\
$\mathrm{FSH}(\mathrm{mlU} / \mathrm{mL})$ & $6.51 \pm 1.2$ & $5.41 \pm 1.3$ & $<0.05$ \\
$\mathrm{LH}(\mathrm{mIU} / \mathrm{mL})$ & $4.30 \pm 1.4$ & $11.91 \pm 2.6$ & $<0.001$ \\
$\mathrm{Basal} \mathrm{LH} / \mathrm{FSH}$ & $0.65 \pm 0.2$ & $2.20 \pm 0.7$ & $<0.001$ \\
$\mathrm{E}_{2}(\mathrm{pg} / \mathrm{mL})$ & $38.5 \pm 4.3$ & $41.2 \pm 9.8$ & $\mathrm{NS}$ \\
Testosterone $(\mathrm{ng} / \mathrm{mL})$ & $0.13 \pm 0.05$ & $0.64 \pm 0.05$ & $<0.001$ \\
Progesterone $(\mathrm{ng} / \mathrm{mL})$ & $0.55 \pm 0.22$ & $0.70 \pm 0.23$ & $\mathrm{NS}$ \\
Antral follicle count & $10.2 \pm 1.1$ & $24.1 \pm 3.7$ & $<0.001$ \\
Oocytes obtained & $8.5 \pm 3.0$ & $17.8 \pm 5.2$ & $<0.001$ \\
No. of MIl oocytes & $6.3 \pm 1.8$ & $14.5 \pm 4.6$ & $<0.001$ \\
No. of 2PN oocytes & $5.7 \pm 1.4$ & $13.8 \pm 3.9$ & $<0.001$ \\
No. of transferable & $4.1 \pm 1.9$ & $8.23 \pm 3.2$ & $<0.001$ \\
embryos (D3) & & &
\end{tabular}

Data are presented as the mean \pm S.E.M.

$\mathrm{NS}$, not statistically significant; $\mathrm{BMI}$, body mass index; $\mathrm{E}_{2}$, oestradiol; $\mathrm{FSH}$, follicle-stimulating hormone; LH, luteotrophic hormone; PCOS, polycystic ovary syndrome; $2 \mathrm{PN}$, two pronuclei in oocytes with normal fertilisation. 
subcutaneously received recombinant FSH (150-187.5IU; Gonal-f, Follitropin Alfa, Serono) for COS. When two or more follicles were at least $18 \mathrm{~mm}$ in diameter and the serum $\mathrm{E}_{2}$ levels were at least $300 \mathrm{pg} / \mathrm{mL}$ per dominant follicle, all patients received $250 \mu \mathrm{g}$ hCG (Profasi; Serono).

\section{Cumulus cell collection}

The cumulus cells were collected as previously described (Huang et al. 2013a,b). Briefly, cumulus-oocyte complex (COC) retrieval was performed by vaginal puncture under ultrasound echo-guidance $36 \mathrm{~h}$ after hCG administration. After COC retrieval, a portion of the CCs surrounding a single oocyte was removed using a sharp needle, lysed in $80 \mu \mathrm{L}$ lysis buffer (mirVana miRNA Isolation Kit; Ambion) and stored at $-80^{\circ} \mathrm{C}$ until RNA extraction. The cumulus cells isolated from the five PCOS and five control patients were used in miRNA and mRNA microarrays. The cumulus cells isolated from others patients (13 PCOS and 13 control patients) were used in qRTPCR and western blotting analyses.

\section{KGN cell culture}

KGN cells were selected and used for a luciferase activity assay and miRNA mimics/inhibitor transfection experiments. KGN (RCB1154; RIKEN, Wako, Japan) is a steroidogenic human ovarian granulosa tumour cell line. The characteristics of the KGN cells are as follows: (1) they showed detectable levels of basal secretion of pregnenolone and progesterone $(\mathrm{P})$, both of which increased after stimulation with $(\mathrm{Bu})_{2}$ CAMP; $(2)$ they showed basal secretion of the $17 \alpha$-hydroxylated steroids, dehydroepiandrosterone androstenedione, and the $E_{2}$ levels were very low or undetectable. All of the above steroids showed no significant change after stimulation with $(\mathrm{Bu})_{2} \mathrm{CAMP}$; and (3) the KGN cells exhibited a relatively high aromatase activity. When the cells were exogenously provided with enough androstenedione or testosterone, the secretion of oestrone and $E_{2}$ by the KGN cells was detectable (Nishi et al. 2001).

In this study, the KGN cells were cultured in 1:1 Dulbecco's modified Eagle's medium and Ham's F-12 medium (DMEM/ F12; Nissui Pharmaceutical, Tokyo, Japan) supplemented with $10 \%$ foetal bovine serum (FBS) and antibiotics $(100 \mathrm{IU} / \mathrm{mL}$ penicillin and $100 \mu \mathrm{g} \mathrm{mL}$ streptomycin). On the day before the luciferase activity assay or the miRNA transfection, the KGN cells were placed into the medium without serum and incubated overnight.

\section{RNA extraction, labelling and hybridisation, and data analysis}

The cumulus cells isolated from one patient (PCOS or control) were pooled together as one sample to extract the total RNA and were analysed individually. Total RNA containing small RNA was extracted from the cumulus cells using the mirVana miRNA Isolation Kit (Ambion) according to the manufacturer's protocols. The purity and concentration of RNA were determined from OD260/280 readings using a spectrophotometer (NanoDrop ND-1000). RNA integrity was determined by capillary electrophoresis using the RNA
6000 Nano Lab-on-a-Chip kit and Bioanalyser 2100 (Agilent Technologies). Only RNA extracts with RNA integrity number values $>6$ underwent further analysis.

miRNA profiling was performed using an Agilent miRNA array. The Agilent array was designed with eight identical arrays per slide $(8 \times 60 \mathrm{~K}$ format), with each array containing probes interrogating 1887 human mature miRNAs from miRBase R18.0. Each miRNA was detected by probes repeated 30 times. The array also contained 2164 Agilent control probes. Microarray experiments were conducted according to the manufacturer's instructions. Briefly, the miRNAs were labelled using the Agilent miRNA labelling reagent. Total RNA (100 ng) was dephosphorylated and ligated with pCp-Cy3, and the labelled RNA was purified and hybridised to miRNA arrays.

mRNA profiling was performed using the Agilent human IncRNA+mRNA Array v2.0 $(4 \times 180 \mathrm{~K}$ format $)$. Each array contains probes that interrogate approximately 39,000 human IncRNAs and approximately 32,000 mRNAs. The array also contained 4974 Agilent control probes. The microarray experiments were conducted according to the manufacturer's instructions as described by our recently published reports (Huang et al. 2016). Briefly, cDNA was labelled with a fluorescent dye (Cy3-dCTP) using the Eberwine's linear RNA amplification method and a subsequent enzymatic reaction. This procedure was improved using the CapitalBio cRNA Amplification and Labelling Kit (CapitalBio Corporation, Beijing, People's Republic of China). The labelled controls and the test samples, labelled with Cy3-dCTP, were dissolved in hybridisation solution. The arrays were hybridised in an Agilent hybridisation oven overnight.

The images were scanned using the Agilent microarray scanner (Agilent), gridded and analysed using Agilent feature extraction software version 10.10. The miRNA or mRNA array data were analysed for data summarisation, normalisation and quality control using GeneSpring software V12 (Agilent) separately. The default 90th (or 75th) percentile normalisation method was performed for the miRNA (or mRNA) array data preprocessing. To select the differentially expressed genes, we used threshold values with $\geq 1.5$ - and $\leq-1.5$-fold changes and a $t$-test with a corrected $P$ value of 0.05. The data were Log2 transformed, and the median was centred by genes using the Adjust Data function of CLUSTER 3.0 software. Next, the data were further analysed using hierarchical clustering with average linkage. Finally, a tree visualisation was performed using Java Treeview (Stanford University School of Medicine, Stanford, CA, USA). The microarray data were analysed by CapitalBio Corporation, Beijing, People's Republic of China.

\section{Target prediction and bioinformatics analysis of miRNAs}

The targeted mRNA of the differentially expressed miRNAs was predicted by miRWalk 2.0 (http://www.umm.uni-heidelberg. de/apps/zmf/mirwalk/index.html) (Dweep et al. 2014). The database included information on miRNA-target interaction produced by several established miRNA prediction programs (i.e. RNA22, miRanda, miRDB, TargetScan, RNAhybrid, PITA, miRWalk) on 3'-UTRs of all known human, mouse and rat 
genes ( $P$ value $\leq 0.05$ ) (Dweep et al. 2011). Next, the miRNApredicted target genes were analysed using a free web-based Molecular Annotation System 3.0 (MAS 3.0; www.capitalbio. com), which integrates three different open-source pathway resources: KEGG, BioCarta and GenMAPP. The significantly represented pathway was chosen by the threshold of the $P$ value and FDR (corrected $P$ value) $<0.05$ derived from the hypergenomic test.

\section{Candidate miRNAs and target gene expressions detected by quantitative real-time PCR}

In this study, the expression levels of candidate miRNAs and target genes were tested by quantitative real-time PCR in additional ten PCOS and ten control samples respectively. To detect the expression of candidate miRNAs, $1 \mu \mathrm{g}$ total RNA was reverse transcribed into cDNA using a miScript Reverse Transcription Kit (Qiagen), and qRT-PCR was performed using the SYBR Green Assay (Takara Bio) according to the manufacturer's protocols. U6 was used as an internal control. The $20 \mu \mathrm{L}$ reaction mixture contained $10 \mu \mathrm{L}$ of $2 \times$ QuantiTest SYBR Green PCR Master mix, $2 \mu \mathrm{L}$ of $10 \times$ miScript Universal Primer, $0.5 \mu \mathrm{L}$ specific miRNA primer, $1 \mu \mathrm{L}$ cDNA template and RNase-free water. The PCR program was as follows: $95^{\circ} \mathrm{C}$ for $10 \mathrm{~min}$, followed by 40 cycles at $95^{\circ} \mathrm{C}$ for $15 \mathrm{~s}$ and $60^{\circ} \mathrm{C}$ for $1 \mathrm{~min}$.

To determine the mRNA expression level of predictive target genes, the first-strand complementary synthesis reaction was performed using a PrimeScript RT reagent kit (Perfect Real Time; TaKaRa Bio). Amplification reactions were conducted using SYBR Premix Ex Taq (Perfect Real Time; TaKaRa Bio) and an ABI PRISM 7300 system. GAPDH was used as an internal reference. The $20 \mu \mathrm{L}$ PCR mixture contained $10 \mu \mathrm{L}$ of $2 \times$ QuantiTest SYBR Green PCR Master mix, $1 \mu \mathrm{L}$ cDNA template, $1 \mu \mathrm{L}$ each primer and RNase-free water. The PCR reactions were performed at $95^{\circ} \mathrm{C}$ for $30 \mathrm{~s}$, followed by 40 cycles of $95^{\circ} \mathrm{C}$ for $5 \mathrm{~s}$ and $60^{\circ} \mathrm{C}$ for $60 \mathrm{~s}$.

Each set of qRT-PCRs was repeated at least three times, and the fold change in the expression of each gene was analysed using the DDCt method (Livak \& Schmittgen 2001). qRT-PCR primers of miRNAs and the target genes are listed in Table S1, see section on supplementary data given at the end of this article.

\section{Western blotting analysis}

The protein levels of miRNA target gene (MAP3K8) in the cumulus cells of PCOS and control patients were analysed using western blotting. Briefly, the protein lysates from cumulus cells were separated by $12 \%$ SDS-PAGE and then transferred onto nitrocellulose membranes (Amersham Biosciences). After blocking in TBST (0.5\% Tween 20 in TBS) containing $5 \%$ non-fat milk powder for $1 \mathrm{~h}$, the membranes were incubated overnight at $4{ }^{\circ} \mathrm{C}$ with an Anti-MAP3K8 antibody (Abcam; ab137589) and a monoclonal anti-GAPDH antibody (Sigma-Aldrich). The blots were then incubated with alkaline phosphatase (AP)-conjugated anti-mouse/rabbit IgG antibody (Promega). AP activity was recorded using the Lumi-Phos Kit (Pierce).

\section{Luciferase reporter constructs and the luciferase activity assay}

Molecular constructs were derived from the pmirGLO vector (Promega) by cloning of the DNA sequences encoding the 3'-UTR of miRNA-509-3p target gene (MAP3K8) downstream of the Renilla luciferase ORF. To construct luciferase reporters with mutations, PCR was performed using two sets of primers to generate two fragments of the 3-UTRs overlapping at the mutation sites. Next, these two fragments were annealed and used as templates to amplify mutated $3^{\prime}$-UTRs. For partial length $3^{\prime}$-UTR cloning, sequences encompassing the putative miRNA binding sites were amplified and cloned into the Sacl and $\mathrm{Xhol}$ restrictions sites.

KGN cells were plated onto 24-well plates and allowed to grow for $\sim 24 \mathrm{~h}$ before transfection. The constructed reporter vectors (300 ng) were transfected into cells together with the miRNA mimics and control mimics (100 nM) in Lipofectamine $2000(2 \mu \mathrm{L})$. Cells were lysed after $\sim 24 \mathrm{~h}$ of transfection, and the luciferase activity was assayed using the Dual-Luciferase Reporter Assay System (Promega). Firefly luciferase activities were normalised to Renilla luciferase activities. The experiments were performed independently in triplicate.

\section{MicroRNA mimics or inhibitor transfections in the KGN cells}

To investigate the relationship between the candidate miRNA (miRNA-509-3p) and the target gene (MAP3K8), miRNA-509-3p mimics or an inhibitor was transfected into the KGN cells. The miRNA-509-3p mimics (forward: 5' - UGAUUGGUACGUCUGUGGGUAG-3'; reverse: $5^{\prime}$-ACCCACAGACGUACCAAUCAUU-3') and the miRNA509-3p inhibitor (5'-CUACCCACAGACGUACCAAUCA-3') were commercially synthesised by Gene Pharma (Shanghai, China). A stable negative control (nc mimic) (forward: 5'-UUCUCCGAACGUGUCACGUTT-3' ; reverse: 5'-ACGUGACACGUUCGGAGAATT-3') and a nc inhibitor (5'-CAGUACUUUUGUGUAGUACAA-3') were used as the negative controls. The mimics and inhibitors of miRNA-509-3p and their scrambled controls were transfected into the KGN cells with Lipofectamine 2000 (Invitrogen). After a 48-h transfection, the expressions of MAP3K8 (mRNA or protein levels) and miRNA-509-3p in the corresponding transfected KGN cells were detected by qRT-PCR and western blotting analyses. Each experiment was performed six times.

\section{Assay for $E_{2}$ secretion in the transfected KGN cells}

Oestradiol secretion in the transfected KGN cells was determined by testing $E_{2}$ accumulation in the culture medium. The transfected KGN cells were plated onto 24-well plates at a density of $1 \times 10^{5}$ viable cells per well and were incubated with $10^{-5} \mathrm{M}$ of $\mathrm{T}$ (testosterone, substrate for $\left.\mathrm{E}_{2}\right)$ and $\mathrm{hMG}(500 \mathrm{mlU} / \mathrm{mL})$. Next, the media were collected after $48 \mathrm{~h}$, and the $\mathrm{E}_{2}$ concentrations were measured by means of the enzyme immunoassay (EIA) Kit (Amerlite P, Amersham Pharmacia, Tokyo, Japan). The intraassay and inter-assay coefficients of variation were $<10 \%$. Each experiment was performed six times independently. 


\section{Statistical analysis}

In this study, all experiments were repeated at least three times. All data were analysed using Student's $t$ test. The values were presented as the mean \pm S.E.M. Statistical analysis was performed using SPSS 13.0 (SPSS). A value of $P<0.05$ was considered to indicate statistical significance.

\section{Results}

\section{Identification of differentially expressed miRNAs and mRNAs between the PCOS and control cumulus cells}

For the miRNA and mRNA expression profiles, the cumulus cells isolated from the five PCOS and five normal patients were analysed using microarrays. The raw microarray data were deposited in NCBI's Gene Expression Omnibus (GEO; http://www.ncbi.nlm.nih. gov/geo/) and can be accessed through the GEO series accession numbers GSE72274 and GSE65746. In total, 17 miRNAs were identified, which were differentially expressed between the PCOS and control cumulus cells (fold change $>1.5$ or $<-1.5 ; P<0.05$ ). As given in Table 2, 16 miRNAs showed an increased expression and one miRNA showed a decreased expression in the PCOS cumulus cells. Among these miRNAs, hsamiRNA-135b-5p ( $\log 2$ fold change $P / N=21.27$ ) was the most up-regulated miRNA, whereas hsa-miRNA3940-5p ( $\log 2$ fold change $P / N=-1.53$ ) was the only down-regulated one. Meanwhile, among the 1263 differentially expressed mRNAs, 1213 mRNAs were up-regulated, whereas 50 mRNAs were downregulated in the PCOS cumulus cells (Table S2). Of these mRNAs, SGCZ (NM_139167) (log 2 fold change $P / N=4.719)$ was the most up-regulated mRNA, and HOXA3 (NM_153631) (log 2 fold change $P / N=-3.943)$ was the most down-regulated one. A clustering analysis based on the differentially expressed mRNAs perfectly clustered the PCOS and the normal groups (Fig. 1).

\section{Differentially expressed miRNA-targeted genes and pathways}

The prediction of miRNA-targeted genes was performed to demonstrate altered gene expression in association with aberrant miRNA profiles in PCOS cumulus cells. Thus, target gene analysis was performed using miRWalk 2.0 (Table S3). As the miRNAs (hsa-miRNA1273e, hsa-miRNA-4659a-3p and hsa-miRNA-652-5p) had no target gene predicted by miRWalk 2.0, we did not further analyse them. For the other miRNAs, the top 100 potential target genes for each miRNA were selected to identify the associated signalling pathways and biological functions. Regarding GO annotation, the associated biological processes, cellular components and molecular function in which these target genes were involved are presented in Tables S4, S5 and S6. We found that the putative target genes of altered miRNAs were involved in a wide range of biological processes, such as the regulation of transcription (GO: 0006355), development (GO: 0007275), protein amino phosphorylation (GO: 0006468) and signal transduction (GO:0007165). Moreover, we enriched the signalling pathways regulated by the predicted genes of altered miRNAs. As shown in Table S7, the pathway with the maximum enriched genes is 'Focal adhesion $(n=27)$ ', followed by (in descending order) 'Regulation of actin cytoskeleton' $(n=25)$, 'ECMreceptor interaction' $(n=15)$, 'MAPK signalling pathway' $(n=23)$ and 'calcium signalling pathway' $(n=19)$.

\section{Comparison of the miRNA-targeted genes and the differentially expressed genes (DEGs) isolated by the cDNA microarray}

Comparing the list of the DEGs isolated from the cDNA microarray (Table S2) and the list of predicted miRNA-targeted genes (Table S3), we found that several miRNA-targeted genes were also identified by the

Table 2 Differentially expressed miRNAs in cumulus cells of the PCOS patients.

\begin{tabular}{lclrrrl}
\hline miRNA name & Fold change & chr & Start & Stop & Strand & Active_sequence \\
\hline hsa-miRNA-135b-5p & 21.26811 & chr1 & 205417467 & 205417445 & + & TCACATAGGAATGAAAAGCCATA \\
hsa-miRNA-152 & 5.63396 & chr17 & 46114600 & 46114586 & + & CCAAGTTCTGTCATGC \\
hsa-miRNA-193a-3p & 5.529378 & chr17 & 29887075 & 29887090 & - & ACTGGGACTTTGTAGGC \\
hsa-miRNA-194-5p & 6.040723 & chr1 & 220291534 & 220291519 & + & TCCACATGGAGTTGCT \\
hsa-miRNA-196a-5p & 8.043263 & chr12 & 54385548 & 54385567 & - & CCCAACAACATGAAACTACC \\
hsa-miRNA-200b-3p & 5.285276 & chr1 & 1102545 & 1102561 & - & TCATCATTACCAGGCAG \\
hsa-miRNA-423-3p & 4.024403 & chr17 & 28444159 & 28444171 & - & ACTGAGGGGCCTCA \\
hsa-miRNA-454-3p & 5.431713 & chr17 & 57215204 & 57215184 & + & ACCCTATAAGCAATATTGCAC \\
hsa-miRNA-455-5p & 7.912167 & chr9 & 116011554 & 116011571 & - & CGATGTAGTCCAAAGGCA \\
hsa-miRNA-4659a-3p & 7.284604 & chr8 & 6602739 & 6602754 & - & CGTTGCCATGTCTAAGA \\
hsa-miRNA-509-3-5p & 2.741761 & chrX & 146341200 & 146341185 & + & CATGATTGCCACGTCTG \\
hsa-miRNA-509-3p & 2.128628 & chrX & 146340353 & 146340338 & + & CTACCCACAGACGTAC \\
hsa-miRNA-513b-5p & 2.300253 & chrX & 146280596 & 146280579 & + & ATAAATGACACCTCCTTGT \\
hsa-miRNA-652-5p & 5.063606 & chrX & 109298587 & 109298601 & - & TGAATGGCACCCTCTC \\
hsa-miRNA-95 & 6.591886 & chr4 & 8007097 & 8007079 & + & TGCTCAATAAATACCCGTTG \\
hsa-miRNA-1273e & 4.261593 & chr17 & 64425136 & 64425157 & - & TCCACTTCCTGGGTTC \\
hsa-miRNA-3940-5p & -1.533231 & chr19 & 6416462 & 6416452 & + & CAGAGCCCGCCC
\end{tabular}




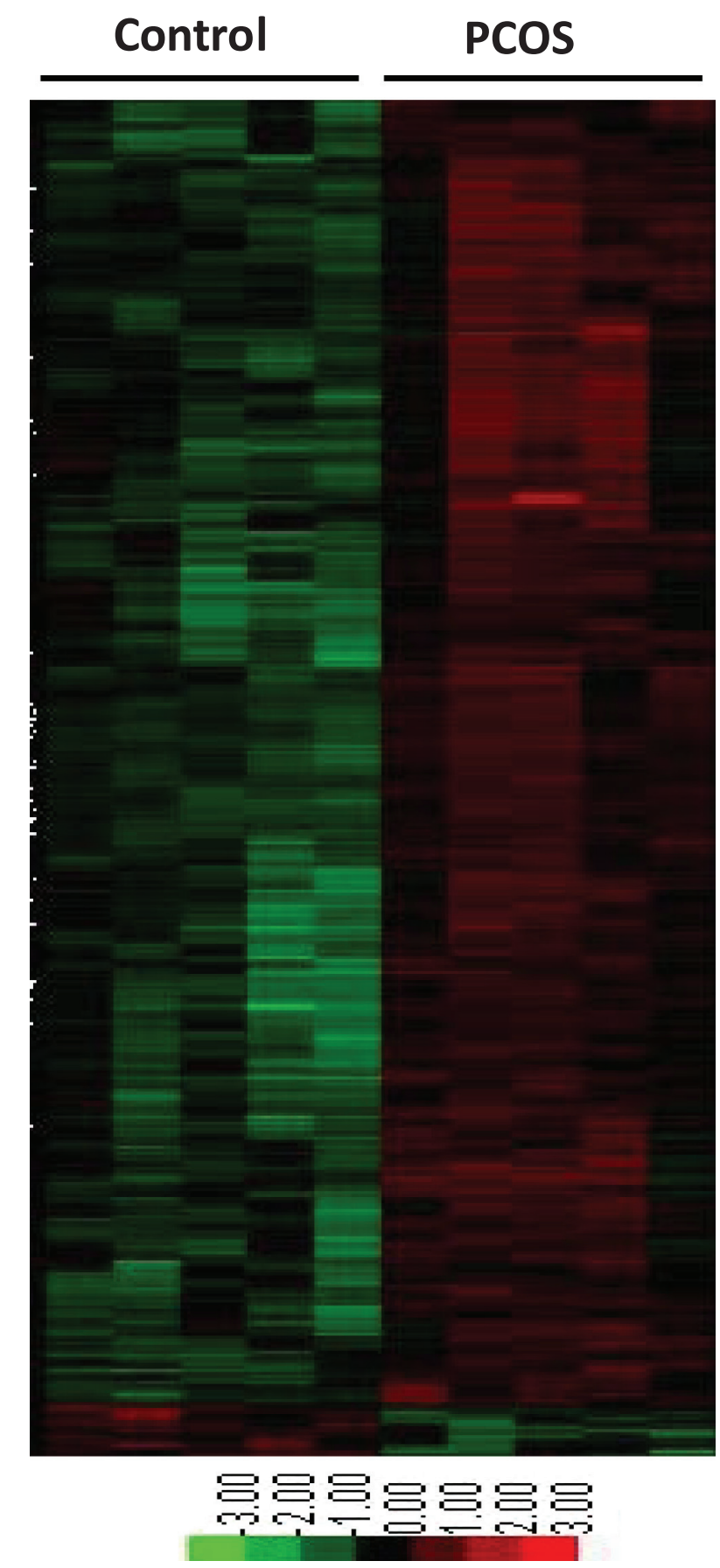

Figure 1 Cluster of mRNAs overexpressed in the cumulus cells from the PCOS patients. This figure shows the supervised hierarchical clustering of the mRNAs overexpressed in the cumulus cells (CCs) from the PCOS patients compared with controls. Distinct signatures in the PCOS and control groups were observed. The value of each mRNA was adjusted by a median-centring algorithm in log scale, and the colours indicated the relative mRNA expression in the red-green heat map. A value of 0 is indicated by pure black colour and represents no change from the median gene expression level in all of the samples. A value of -3 is indicated by pure green colour and represents a relative lower expression. A value of +3 is indicated by pure red colour and represents a relative higher expression.
mRNA microarray (Table 3). For example, MAP3K8 (mitogen-activated protein kinase kinase 8 , a predictive miRNA-509-3p target gene), RND3 (Rho family GTPase 3, a predictive miRNA-200b-3p target gene) and MEIS2 (Meis homeobox 2, a predictive miRNA-194-5p target gene) were down-regulated in the PCOS cumulus cells respectively. In addition, three miRNA-3940$5 p$-predictive target genes (adducin 2 (beta), ADD2; nucleosome assembly protein 1-like 2, NAP1L2; and sodium channel, voltage-gated, type IV, beta, SCN4B) were up-regulated in the PCOS cumulus cells.

\section{Validation of the microarray results by quantitative RT-PCR}

To validate the differentially expressed miRNA and mRNA profiles, the cumulus cell samples isolated from 20 additional samples (ten PCOS patients and ten controls), respectively, were used to extract the RNA for the qRT-PCR. Seven altered miRNAs, including six up-regulated miRNAs (miRNA-509-3p, miRNA513b-5p, miRNA-423-3p, miRNA-200b-3p, miRNA194-5p and miRNA-135b-5p) and one down-regulated miRNA (miRNA-3940-5p), were selected to validate the microarray data. Among these miRNAs, three (miRNA509-3p, miRNA-513b-5p and miRNA-423-3p) were identified in the PCOS cumulus cells by next-generation sequencing (Liu et al. 2015, Xu et al. 2015). miRNA$135 b-5 p$ is the miRNA with the highest FC value in our microarray data. In addition, four miRNAs (miRNA509-3p, miRNA-200b-3p, miRNA-194-5p and miRNA3940-5p) were selected because their predictive target genes were also identified in our cDNA microarray data. At the same time, four predictive miRNAs target genes (MAP3K8, RND3, MEIS2 and NAP1L2) were also selected to confirm the cDNA microarray data by qRTPCR. The results showed that all the seven miRNAs and four mRNAs were detected in all of the samples, and the expression patterns of these genes (miRNAs or mRNAs) measured by qRT-PCR were in concordance with the miRNA or CDNA microarray data (Fig. 2), indicating that our miRNA and mRNA microarray data were reliable.

\section{Confirmation of the direct interaction between miRNA- 509-3p and its predictive target gene (MAP3K8)}

Using the GO annotation and pathway analysis, we found that two predictive miRNA-509-3p target genes, MAP3K 8 and IL1A (interleukin 1, alpha), were involved in the MAPK signalling pathway (Tables S2 and S4). According to our cDNA microarray data, MAP3K8 was down-regulated in the PCOS cumulus cells, whereas ILIA showed no significant changes in the PCOS cumulus cells compared with the control patients (Table S2). Thus, we hypothesised that it was more possible that miRNA-509-3p regulated MAP $3 K 8$ directly in the PCOS cumulus cells. 
Table 3 Differentially expressed miRNAs in the PCOS cumulus cells and their predicted target genes that also identified in cDNA microarray.

\begin{tabular}{|c|c|c|c|c|c|c|c|}
\hline miRNA & Mirbase accession no. & $\begin{array}{l}\text { FC } \\
(P / N)\end{array}$ & miRNA regulation & $\begin{array}{l}\text { Target gene } \\
\text { symbol }\end{array}$ & $\begin{array}{l}\text { Genbank } \\
\text { accession }\end{array}$ & $\begin{array}{l}\text { FC } \\
(P / N)\end{array}$ & mRNA regulation \\
\hline hsa-miRNA-509-3p & MIMAT0002881 & 2.129 & Up & МАРЗК 8 & NM_005204 & 1.615 & Down \\
\hline hsa-miRNA-200b-3p & MIMAT0000318 & 5.285 & Up & RND3 & NM_005168 & 2.713 & Down \\
\hline hsa-miRNA-194-5p & MIMAT0000460 & 6.041 & Up & MEIS2 & NM_170677 & 1.535 & Down \\
\hline \multirow[t]{2}{*}{ hsa-miRNA-3940-5p } & MIMAT0019229 & 1.533 & down & $A D D 2$ & NM_017488 & 1.777 & Up \\
\hline & & & & $\begin{array}{l}\text { NAP1L2 } \\
\text { SCN4B }\end{array}$ & $\begin{array}{l}\text { NM_021963 } \\
\text { NM_174934 }\end{array}$ & $\begin{array}{l}2.227 \\
1.621\end{array}$ & $\begin{array}{l}U p \\
U p\end{array}$ \\
\hline
\end{tabular}

FC, fold change in microarray; P/N, PCOS vs normal.

To confirm the negative correlation between miRNA509-3p and MAP3K8, we again evaluated the mRNA and protein expression levels of MAP3K8 in three additional PCOS and three additional control cumulus cells. We found that both the mRNA and protein levels of MAP3K8 were markedly decreased, whereas the expression level of miRNA-509-3p was significantly increased in the PCOS cumulus cells (Fig. $3 \mathrm{~A}$ and B). These results proved that a negative correlation between miRNA-509-3p and MAP3K8 in the PCOS cumulus cells really exists.

Next, to determine whether MAP3K8 mRNA is a direct target of miRNA-509-3p, we constructed luciferase reporter constructs by cloning the DNA segment-encoding part of the WT or mutant (which cannot bind miRNA-509-3p) 3'-UTR of MAP3K8 mRNA downstream of the Renilla luciferase gene (Fig. 4A) and transfected them with miRNA-509-3p mimics into the $\mathrm{KGN}$ cells. As shown in Fig. 4B, a significant decrease in the relative luciferase activity was detected in the $\mathrm{KGN}$ cells co-transfected with the MAP3K8 WT constructs and the miRNA-509-3p mimics but not in the cells co-transfected with the MAP3K 8 mutant constructs and the miRNA-509-3p mimics. Thus, the above findings demonstrated that miRNA-509-3p suppresses the expression of MAP $3 K 8$ in the cumulus cells by directly binding to the $3^{\prime}$-UTR of MAP3K8 mRNA.

In addition, to further determine the regulation of miRNA-509-3p on MAP3K8, the KGN cells were transfected with the miRNA-509-3p mimics or a miRNA-509-3p inhibitor or their controls. The results showed that the miRNA-509-3p mimics dramatically up-regulated the endogenous miRNA-509-3p (Fig. 5A), and the miRNA-509-3p inhibitor significantly downregulated the expression of miRNA-509-3p (Fig. 5B). Next, we assessed the effects of the miRNA-509-3p mimics and the inhibitor on MAP3K8 expression in the KGN cells. These data showed that the mRNA and protein expression levels of MAP3K8 were decreased by approximately two-fold (Fig. 5C) and 2.04-fold (Fig. 5E and G) in the miRNA-509-3p mimic-transfected KGN cells respectively. In addition, in the miRNA509-3p inhibitor-transfected KGN cells, the mRNA and protein expression levels of MAP3K8 were increased by approximately 2.84-fold (Fig. 5D) and 1.63-fold (Fig. 5F and $\mathrm{H}$ ) respectively. In combination with the results from the $3^{\prime}$-UTR luciferase reporter study, we conclude that miRNA-509-3p directly targets and inhibits MAP $3 K 8$.

\section{miRNA-509-3p promotes $E_{2}$ production in the $K G N$ cells}

To further determine the molecular role of miRNA509-3p in regulating MAP3K8, we determined the $\mathrm{E}_{2}$ production in the medium of the KGN cells transfected
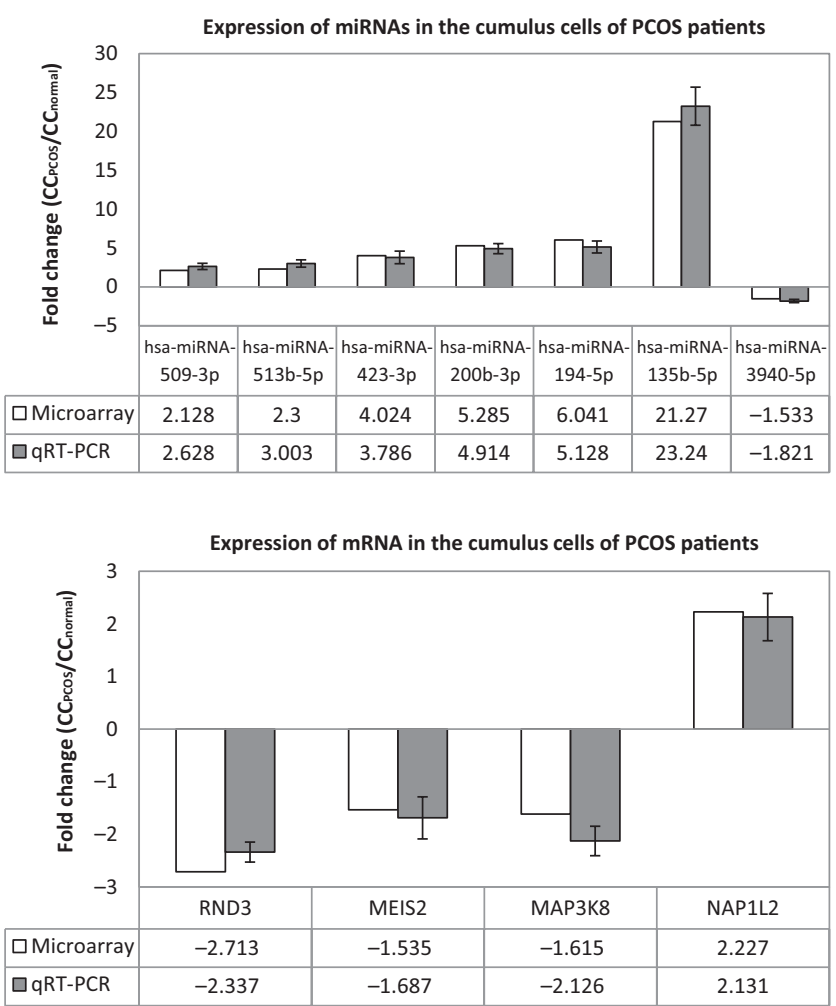

Figure 2 Differentially expressed miRNAs (hsa-miRNA-509-3p, hsa-miRNA-513b-5p, hsa-miRNA-423-3p, hsa-miRNA-200b-3p, hsa-miRNA-194-5p, hsa-miRNA-135b-5p and hsa-miRNA-3940-5p) and their potential target genes (MAP3K8, RND3, MEIS2 and NAP1L2) studied through microarray experiments and validated by qRT-PCR. The qRT-PCR results were in line with the microarray data sets. The grey bars show the relative gene expression measured using qRT-PCR. The white bars show the relative gene expression measured using the microarrays. The same cumulus cells isolated from 20 additional samples (ten from PCOS patients and ten from controls) were used for the qRT-PCR. The selected genes are shown on the $x$-axis and the $y$-axis represents the fold change $\mathrm{CC}_{\mathrm{PCOS}} / \mathrm{CC}_{\text {control }}$. 

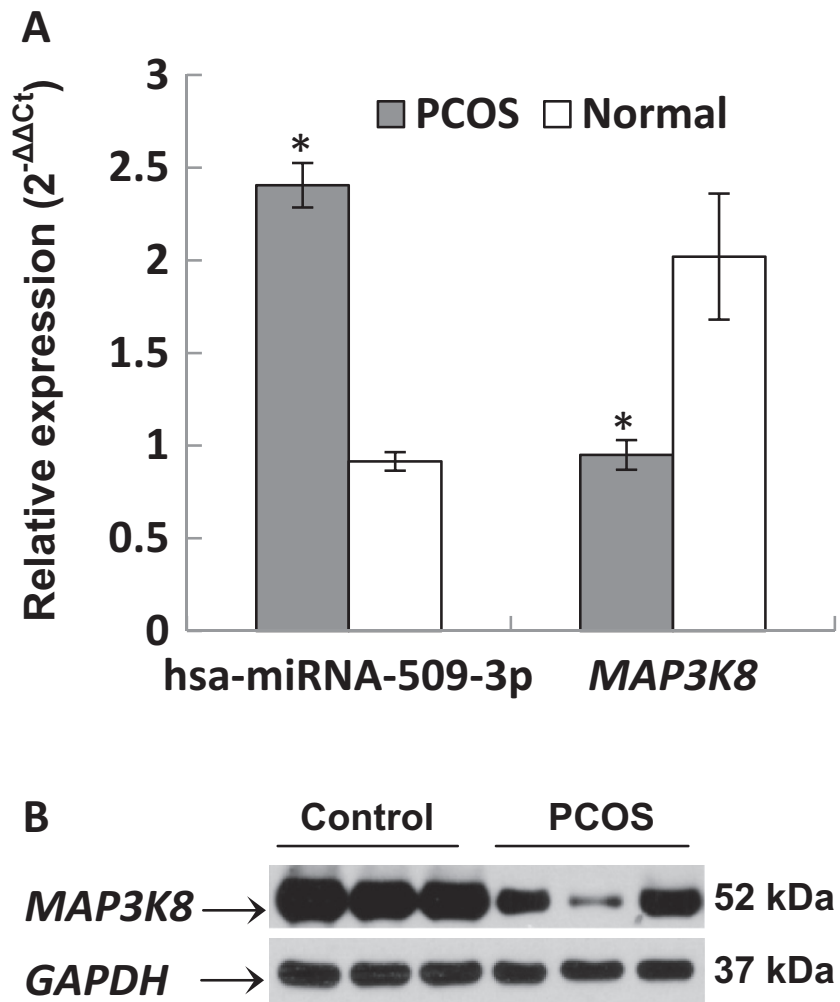

Figure 3 The expression levels of has-miRNA-509-3p and its predictive target gene (MAP3K8) in the cumulus cells of PCOS patients. (A) The mRNA expression levels of miRNA-509-3p and MAP3K 8 detected by qRT-PCR. The expression level of MAP $3 K 8$ was markedly decreased, whereas the expression level of miRNA-509-3p was significantly increased in the PCOS cumulus cells. The signal intensity of the genes is shown on the $y$-axis in arbitrary units determined by qRT-PCR. GAPDH and U6 were used as internal controls for MAP3K8 or miRNA-509-3p respectively. The asterisk (*) indicates a significant difference in the gene expression between the CC categories $(P<0.05)$. The results are presented as the mean \pm S.E.M. (B) The protein levels of the miRNA target gene (MAP3K8) in the cumulus cells of the PCOS and control patients were analysed by western blot. The protein level of MAP3K8 was markedly decreased in the PCOS CCs compared with the control CC samples.

with the miRNA-509-3p mimics or the inhibitor. $E_{2}$ secretion in the medium of the KGN cells increased (2.79-fold) by hMG after adding $\mathrm{T}$ for $48 \mathrm{~h}$. Interestingly, after adding $\mathrm{T}$ and $\mathrm{hMG}$ into the medium for $48 \mathrm{~h}$, the medium from the KGN cells transfected with the miRNA509-3p mimics showed an increased $E_{2}$ secretion (2.36fold) compared with the KGN cells without transfection. Meanwhile, compared with the KGN cells without transfection, the $E_{2}$ secretion was decreased (1.69-fold) in the medium from the KGN cells transfected with the miRNA-509-3p inhibitor (Fig. 6).

\section{Discussion}

Folliculogenesis is a complex process that involves endocrine and intro-ovarian paracrine interactions to provide the most appropriate microenvironment for

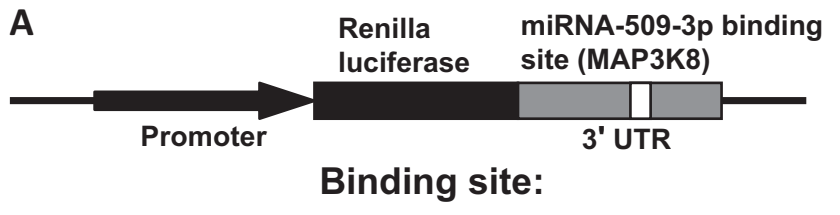

hsa-miRNA-509-3p : gaugggugucugcAUGGUUAGU

MAP3K8 Wild type: tcaaaatttt aaaaaTACCA ATCAcaagga

Mutant: tcaaaatAtt aaTaaATGGT TAGTcaagga

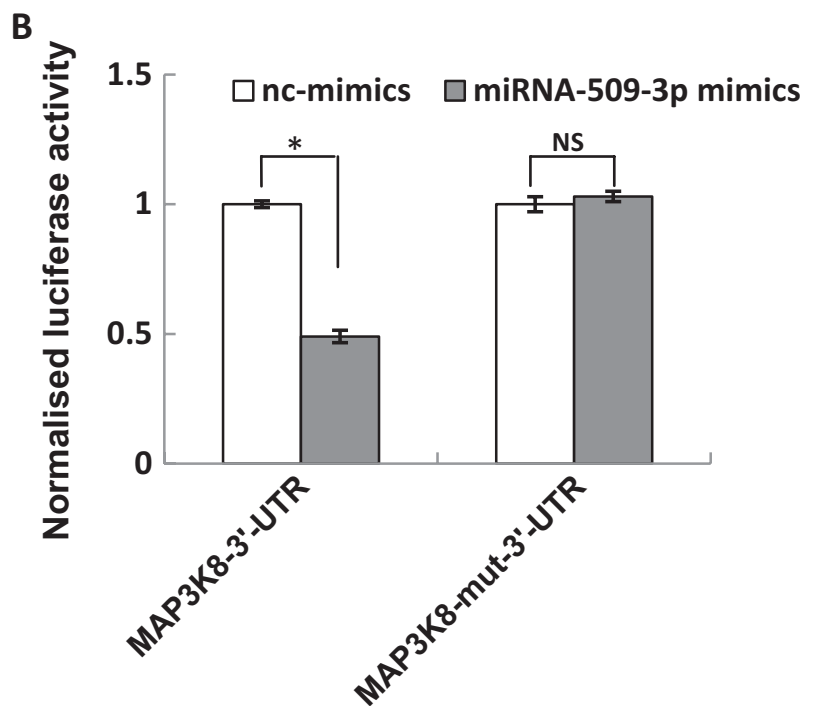

Figure 4 Validation that miRNA-509-3p directly targets MAP3K8 by the luciferase activity assay. (A). Illustration of the construction of the pmirGLO-MAP3K8 UTR vectors. The DNA fragment encoding the $3^{\prime}-U T R$ of the MAP3K 8 mRNA that contains the predicted wild-type or mutant miRNA-509-3p binding site was cloned downstream of the Renilla luciferase ORF in the pmirGLO vector. (B) The relative luciferase activity was assayed following co-transfection of miRNA-509-3p mimics with the constructs encoding the wild-type or mutant miRNA-509-3p binding site of MAP3K8 3'-UTR into the KGN cells. The constructed reporter vectors (MAP3K8-3'-UTR and MAP3K8-mut-3'-UTR) are shown on the $x$-axis, and the $y$-axis represents the normalised luciferase activity (firefly luciferase activities were normalised to Renilla luciferase activities). The experiments were performed independently in triplicate. ${ }^{*} P<0.05$. NS, no significant difference. The results are presented as the mean \pm S.E.M.

oocyte development. The cross talk between the oocyte and the cumulus cells in the microenvironment plays an important role in the acquisition of the development competency of the oocyte (Haouzi et al. 2012). In this study, to elucidate the mechanism of the abnormal folliculogenesis of PCOS, we reported the miRNA and mRNA expression profiles using the same cumulus cell samples isolated from PCOS and control patients. To the best of our knowledge, there are only three recently published reports (Liu et al. 2015, Shi et al. 2015, Xu et al. 2015), similar to ours, that identified the altered 

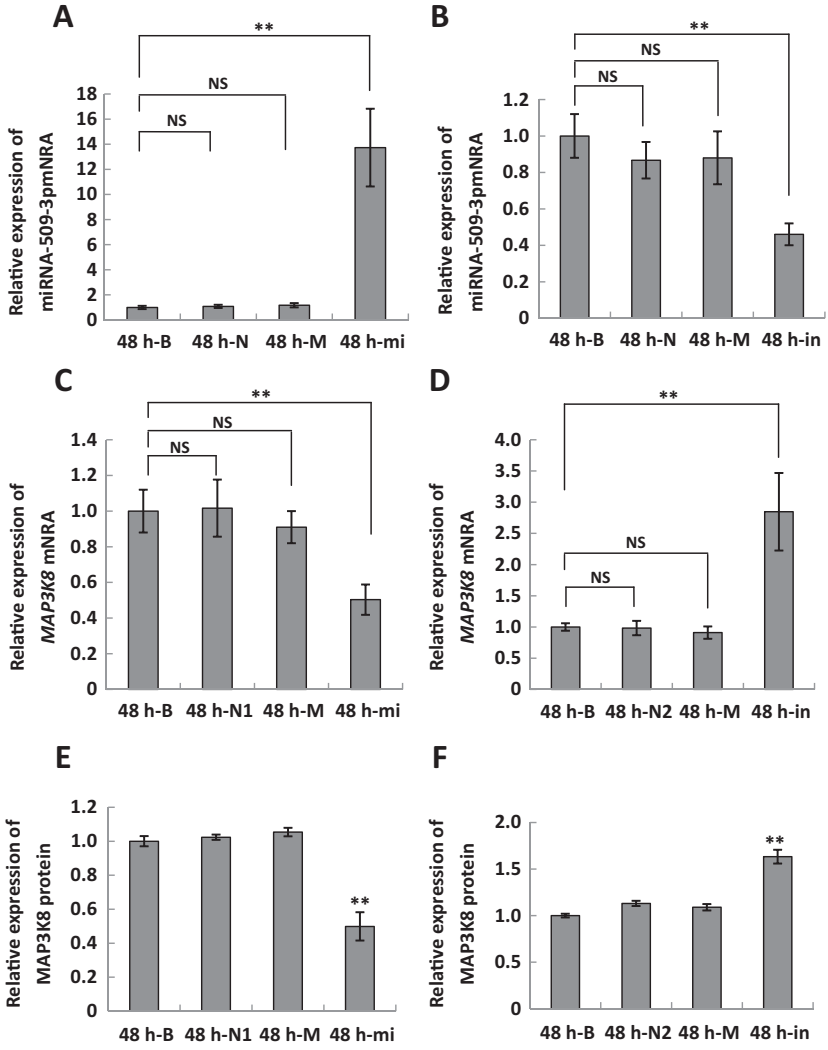

G

$\mathbf{F}$

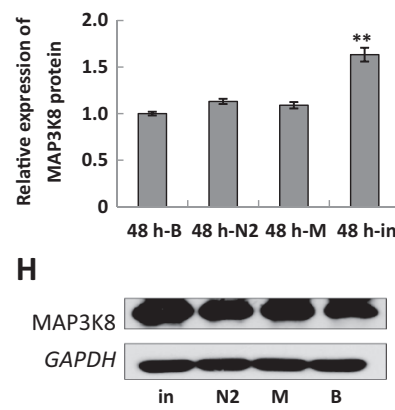

Figure 5 The expression levels of miRNA-509-3p and its target gene (MAP3K8) in the KGN cells transfected with the miRNA-509-3p mimics or inhibitor. After transfection for $48 \mathrm{~h}$, the expression of MAP3K8 (mRNA or protein levels) and miRNA-509-3p in the transfected KGN cells was detected by qRT-PCR and western blotting analyses. The mRNA expression levels of miRNA-509-3p in the KGN cells transfected with the miRNA-509-3p mimics (A) or the inhibitor (B) are shown. The mRNA or protein expression levels of MAP3K 8 in the KGN cells transfected with the miRNA-509-3p mimics (C, E and G) or the inhibitor $(\mathrm{D}, \mathrm{F}$ and $\mathrm{H})$ are also shown. The relative expression of mRNA or protein is shown on the $y$-axis. GAPDH and $U 6$ were used as the internal controls for MAP3K8 or miRNA-509-3p respectively. ${ }^{* *} P<0.01$. NS, no significant difference. The results are presented as the mean \pm S.E.M. Each experiment was performed six times. B, blank; $M$, scramble controls; N1, stable negative control for miRNA-509-3p mimics; N2, stable negative control for miRNA-509-3p inhibitor; mi, miRNA-509-3p mimics; in, miRNA-509-3p inhibitor.

miRNA profiles of PCOS patients using cumulus cells as the study material. By comparing the lists of the differentially expressed miRNAs in our data to that of the previous reports (Liu et al. 2015, Shi et al. 2015, Xu et al. 2015), we found that the miRNA profiles were not exactly the same. This difference may be due to two reasons. First, different molecular technology (miRNA microarray or next-generation sequencing) was used in these studies. Specifically, miRNA microarray was used in our study and in Shi's study (Shi et al. 2015),

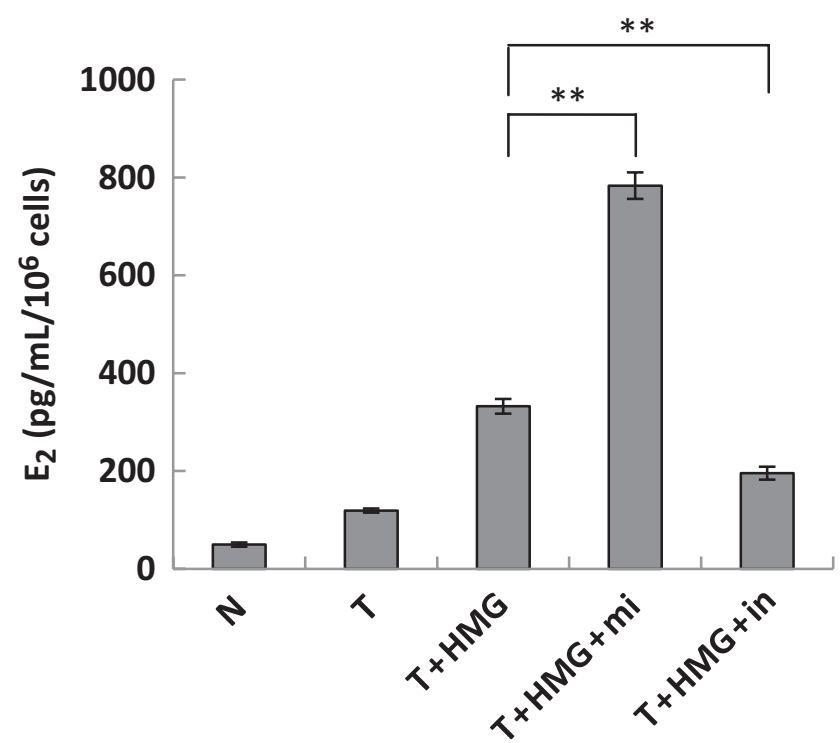

Figure 6 Effect of miRNA-509-3p on $E_{2}$ production in the KGN cells. The transfected KGN cells were plated onto 24-well plates at a density of $1 \times 10^{5}$ viable cells per well and incubated with $10^{-5} \mathrm{M}$ of $\mathrm{T}$ (substrate for $\mathrm{E}_{2}$ ) and $\mathrm{hMG}(500 \mathrm{mIU} / \mathrm{mL})$. Then, the media were collected after $48 \mathrm{~h}$, and the concentration of $\mathrm{E}_{2}$ in the corresponding medium was measured by EIA. The intra-assay and inter-assay coefficients of variation were $<10 \%$. Each experiment was performed six times independently. The data are presented as the mean \pm S.E.M. ${ }^{*} P<0.05,{ }^{* *} P<0.01 . N$, negative control (KGN cells that are not transfected); $T$, testosterone; hMG, human menopausal gonadotropin; mi, miRNA-509-3p mimics; in, miRNA-509-3p inhibitor.

whereas next-generation sequencing was used in Xu's (Xu et al. 2015) and Liu's (Liu et al. 2015) studies. Generally, many novel miRNAs are found by nextgeneration sequencing; however, only the miRNAs with a response to the probes that are included in the microarray can be detected using a miRNA microarray. In fact, in Xu's report (Xu et al. 2015), which isolated 59 differentially expressed miRNAs in the cumulus cells, more than ten miRNAs were novel. Second, we found that in other research (Liu et al. 2015, Shi et al. 2015, Xu et al. 2015), only cumulus-oocyte complexes with mature oocytes (MII) were included. However, in our study, cumulus-oocyte complexes with mature (MII) and immature (MI or GV) oocytes were all selected. Notably, despite receiving significantly less FSH, there were more follicles on the day of oocyte retrieval from the PCOS patients during IVF. Moreover, the ratio of immature oocytes of the PCOS patients was always higher than that of the normal patients. In our previous report (Huang et al. 2013a), we found that the gene expression profiles from cumulus cells isolated from $\mathrm{MI}$ and MII oocytes of PCOS were significantly different. In other words, oocyte nuclear maturation in PCOS is regulated by different genes. These differentially expressed genes may be regulated by different miRNAs in a post-transcriptional manner. The altered miRNAs play different roles during oocyte maturation in PCOS. 
Although there are differences between our study and previous reports, we are excited to find that several miRNAs in our research were also identified in previous reports (Liu et al. 2015, Shi et al. 2015, Xu et al. 2015). For example, the expression of miRNA-509-3p was increased in the PCOS cumulus cells, according to Liu's (Liu et al. 2015), Shi's (Shi et al. 2015) and our data, with almost the same fold changes (2.2-fold in Liu's, 1.8fold in Shi's and 2.13-fold in ours). miRNA-513b-5p, a miRNA isolated in Xu's (Xu et al. 2015), Liu's (Liu et al. 2015) and our research, also showed an up-regulated expression in the PCOS cumulus cells. In addition, in both Xu's (Xu et al. 2015) and our data, miRNA-423-3p showed an increased expression in the PCOS cumulus cells. These data indicate that when the same miRNAs (miRNA-509-3p, miRNA-513b-5p and miRNA-423-3p) are identified by different groups, they are more credible and attract greater research interest in their important roles in abnormal folliculogenesis of PCOS.

It is worth mentioning that another feature of our study is that we identified the miRNA and mRNA expression profiles together by using the same cumulus cell samples of the PCOS and control patients, whereas only the altered miRNAs from the PCOS cumulus cells were isolated in other reports (Liu et al. 2015, Shi et al. 2015, Xu et al. 2015). In addition, we compared the list of the DEGs from the mRNA microarray to the list of potential target genes of each altered miRNA identified by our miRNA microarray to find the potential associated miRNA-mRNA pairs in PCOS. Further research examining the functions of the associated miRNAs and their potential target mRNAs facilitates in the understanding of their roles in the pathogenetic development of PCOS. Coincidentally, we found that MAP3K8, the predicted target gene of miRNA-509-3p, was also identified from our mRNA microarray data. In our experiments, the expression level of miRNA509-3p was increased, whereas the mRNA and protein expression levels of MAP $3 K 8$ were decreased in the PCOS cumulus cells. Moreover, we demonstrated that miRNA-509-3p regulated MAP3K8 expression by directly binding the $3^{\prime}$-UTR of mRNA based on bioinformatics and experimental validation.

According to the $\mathrm{GO}$ and pathway analysis, MAP3K8 was predicted to be involved in the MAPK signalling pathway. The MAPK signalling pathway participates in $\mathrm{LH}$ - and $\mathrm{FSH}$-induced steroidogenesis in granulosa cells (Seger et al. 2001). Actually, granulosa cells from PCOS produce more $E_{2}$ under basal $F S H$ and insulin stimulation, and the enzymes for steroids synthesis in the granulosa cells from PCOS may be active in vivo (Wang et al. 1998). Moreover, the follicular fluid steroid levels and in vitro studies of oestradiol production by granulosa cells isolated from PCOS clearly demonstrated that the granulosa cells of follicles from anovulatory women with PCOS remain steroidogenically active. In addition, abnormal (increased) oestradiol production in the follicles from PCOS appears to be a function of the ovulatory status of the patient rather than the polycystic morphology per se (Franks et al. 1998). To investigate whether miRNA-509-3p and MAP3K8 regulate $\mathrm{E}_{2}$ production, miRNA-509-3p mimics and an inhibitor were transfected into the $\mathrm{KGN}$ cells, respectively, to determine the $\mathrm{E}_{2}$ accumulation in the corresponding culture medium. The results indicate that miRNA-509-3p improves $E_{2}$ secretion by inhibiting the expression of MAP3K8.

MAP3K8 is a serine-threonine kinase with crucial physiological roles in $\mathrm{G}$ protein-coupled receptormediated extracellular signal regulated kinase (ERK), tumour necrosis factor, interleukin-1, CD40 and Tolllike receptor signal transduction (Hatziapostolou et al. 2008). A previous report demonstrated that MAP3K8 enhances ERK1/2 phosphorylation (Ceci et al. 1997), and it had been confirmed that ERK1/2 phosphorylation inhibits $E_{2}$ production via the MAPK signalling pathway in human granulosa cells (Deura et al. 2005). In addition, it has been verified that (ERK1/2) phosphorylation was decreased in PCOS theca cells compared with normal cells (Nelson-Degrave et al. 2005). This finding is consistent with the phenomenon that there is a high oestrogen production from the granulosa cells in PCOS patients under basal FSH stimulation (Wang et al. 1998). Thus, we speculated that ERK1/2 was the downstream molecular target of miRNA-509-3p and MAP3K8. miRNA-509-3p mediates the MAPK signalling pathway to regulate $\mathrm{E}_{2}$ production by targeting MAP3K8.

Although miRNA-513b-5p and miRNA-423-3p were also regarded as altered miRNAs in the PCOS cumulus cells in our research and previous research (Liu et al. 2015, Shi et al. 2015, Xu et al. 2015), the potential target genes of miRNA-513b-5p or miRNA-423-3p were not included in the list of the DEGs in the PCOS cumulus cells that were identified in our mRNA microarray data.

miRNA-423-3p was up-regulated in the PCOS cumulus cells based on our and Xu's results (Xu et al. 2015). Previous research on laryngeal carcinoma reported that miRNA-423-3p directly interacts with AdipoR2 (adiponectin receptor 2) and promotes tumour progression (Guan et al. 2014). AdipoR2 is a receptor to adiponectin, which is a predominantly adipocytederived hormone that influences insulin sensitivity and energy homeostasis. In animal models, adiponectin may regulate ovarian steroidogenesis, folliculogenesis and ovulation (Chabrolle et al. 2007). Moreover, it has been demonstrated that a significantly lower proportion of theca cells express AdipoR2 in polycystic ovaries than in normal ovaries, and the disruption of adiponectin and/or its receptors plays a key role in the pathogenesis of hyperandrogenism in PCOS (Comim et al. 2013) and impairs normal progesterone production (Wickham et al. 2013). In view of the results of the above reports, although the miRNA-423-3p potential target genes were not detected in our cDNA microarray, we also 
determined the expression levels of AdipoR2 in the PCOS or control cumulus cells by qRT-PCR. Consistent with the cDNA microarray data, the expression of AdipoR2 showed no significant difference between the two groups (PCOS and control) (data not shown). The results may be associated with the fact that the adiponectin levels are not reduced in all PCOS patients. Dividing the patients (PCOS or control) into subgroups, such as obese or lean subgroups, according to their BMI may provide more information regarding the function of miRNA-423-3p and AdipoR2.

Another miRNA, miRNA-513b-5p, inhibits cell proliferation and migration and promotes apoptosis by targeting high-mobility group-box 3 protein (HMGB3) in gastric cancer (Chen et al. 2014). With regard to PCOS, the apoptosis level is increased in the granulosa cells (Onalan et al. 2005, Lin et al. 2012); thus, we considered that the up-regulated miRNA-513b-5p in the PCOS cumulus cells might participate in the regulation of apoptosis with an impact on the atretic process of the follicles, leading to follicle maturation disorder. However, the target genes or the regulation of miRNA$513 b-5 p$ in the occurrence of PCOS need to be further researched.

In summary, we isolated the differentially expressed miRNA and mRNA profiles in the cumulus cells from PCOS patients by microarrays. The expression levels of candidate miRNAs and their potential target genes were detected by qRT-PCR to confirm the microarray data. In this study, miRNA-509-3p, miRNA-513b-5p and miRNA423-3p were up-regulated in the PCOS cumulus cells, which were also shown in previous data. In particular, as the potential target gene of miRNA-509-3p, MAP3K8 was also detected in our cDNA microarray and showed a down-regulated expression in the PCOS cumulus cells. Next, we verified that miRNA-509-3p regulated MAP3K8 expression by directly binding the $3^{\prime}-U T R$ of mRNA based on the luciferase activity assay. The experiments transfecting the miRNA-509-3p mimics or the inhibitor in the $\mathrm{KGN}$ cells and the $\mathrm{E}_{2}$ production determination in the corresponding medium further confirmed that miRNA-509-3p improves $\mathrm{E}_{2}$ secretion by inhibiting MAP3K 8 expression. These results will help to characterise the pathogenesis of anovulation in PCOS, especially the regulation of oestradiol secretion.

\section{Supplementary data}

This is linked to the online version of the paper at http://dx.doi. org/10.1530/REP-16-0071.

\section{Declaration of interest}

The authors declare that there is no conflict of interest that could be perceived as prejudicing the impartiality of the research reported.

\section{Funding}

This study was supported by the National Natural Science Foundation of China (Grant 81401172), the Natural Science Foundation of Shandong Province (Grant ZR2013HQ004) and the Yantai Science and Technology Development Project (Grant 2015YT06000550).

\section{Author contribution statement}

Xin Huang and Chang Liu involved in the design, experiments, analysis and interpretation; drafting; and final approval of the manuscript. Cuifang Hao contributed to the design, revisions to manuscript and final approval of the manuscript. Qianqing Tang involved in oestradiol determination and data acquisition. Riming Liu involved in oestradiol determination. Shaoxia Lin and Luping Zhang contributed to experiments (qRT-PCR, western blotting and luciferase activity assay), and Wei Yan contributed to cumulus cell collection and final approval of the manuscript.

\section{Acknowledgements}

The authors gratefully acknowledge the CapitalBio Corporation for conducting the RNA extractions and microarrays.

\section{References}

Carletti MZ \& Christenson LK 2009 MicroRNA in the ovary and female reproductive tract. Journal of Animal Science 87 E29-E38.

Carmina E 2009 Cardiovascular risk and events in polycystic ovary syndrome. Climacteric 12 (Supplement 1) 22-25. (doi:10.1080/13697130903003842)

Ceci JD, Patriotis CP, Tsatsanis C, Makris AM, Kovatch R, Swing DA, Jenkins NA, Tsichlis PN \& Copeland NG 1997 Tpl-2 is an oncogenic kinase that is activated by carboxy-terminal truncation. Genes \& Development 11 688-700.

Chabrolle C, Tosca L \& Dupont J 2007 Regulation of adiponectin and its receptors in rat ovary by human chorionic gonadotrophin treatment and potential involvement of adiponectin in granulosa cell steroidogenesis. Reproduction 133 719-731. (doi:10.1530/REP-06-0244)

Chen YH, Heneidi S, Lee JM, Layman LC, Stepp DW, Gamboa GM, Chen BS, Chazenbalk G \& Azziz R 2013 miRNA-93 inhibits GLUT4 and is overexpressed in adipose tissue of polycystic ovary syndrome patients and women with insulin resistance. Diabetes 62 2278-2286. (doi:10.2337/db12-0963)

Chen X, Zhao G, Wang F, Gao F, Luo H, Wang Y, Du Y, Xue C, Dong Z \& Song G 2014 Upregulation of miRNR-513b inhibits cell proliferation, migration, and promotes apoptosis by targeting high mobility groupbox 3 protein in gastric cancer. Tumor Biology 35 11081-11089. (doi:10.1007/s13277-014-2405-z)

Christakou C \& Diamanti-Kandarakis E 2014 Polycystic ovary syndrome phenotypes and diagnosis. Scandinavian Journal of Clinical and Laboratory Investigation. Supplementum 244 18-22. (doi:10.3109/003 65513.2014.936675)

Comim FV, Hardy K \& Franks S 2013 Adiponectin and its receptors in the ovary: further evidence for a link between obesity and hyperandrogenism in polycystic ovary syndrome. PLOS ONE 8 e80416.

Deura I, Harada T, Taniguchi F, Iwabe T, Izawa M \& Terakawa N 2005 Reduction of estrogen production by interleukin- 6 in a human granulosa tumor cell line may have implications for endometriosisassociated infertility. Fertility and Sterility $\mathbf{8 3}$ (Supplement 1) 1086-1092.

Diao FY, Xu M, Hu Y, Li J, Xu Z, Lin M, Wang L, Zhou Y, Zhou Z, Liu J et al. 2004 The molecular characteristics of polycystic ovary syndrome (PCOS) ovary defined by human ovary cDNA microarray. Journal of Molecular Endocrinology 33 59-72. (doi:10.1677/jme.0.0330059) 
Donadeu FX, Schauer SN \& Sontakke SD 2012 Involvement of miRNAs in ovarian follicular and luteal development. Journal of Endocrinology 215 323-334. (doi:10.1530/JOE-12-0252)

Dweep H, Sticht C, Pandey P \& Gretz N 2011 miRWalk - database: prediction of possible miRNA binding sites by "walking" the genes of three genomes. Journal of Biomedical Informatics 44 839-847. (doi:10.1016/j.jbi.2011.05.002)

Dweep H, Gretz N \& Sticht C 2014 miRWalk database for miRNAtarget interactions. Methods in Molecular Biology 1182 289-305. (doi:10.1007/978-1-4939-1062-5)

Franks S, Mason HD, Polson DW, Winston RM, Margara R \& Reed MJ 1988 Mechanism and management of ovulatory failure in women with polycystic ovary syndrome. Human Reproduction 3 531-534.

Franks S, Mason H, White D \& Willis D 1998 Etiology of anovulation in polycystic ovary syndrome. Steroids 63 306-307. (doi:10.1016/S0039128X(98)00035-X)

Fux Otta C, Fiol de Cuneo M \& Szafryk de Mereshian P 2013 [Polycystic ovary syndrome: physiopathology review]. Revista de la Facultad de Ciencias Médicas de Córdoba 70 27-30.

Group REA-SPCW 2004 Revised 2003 consensus on diagnostic criteria and long-term health risks related to polycystic ovary syndrome. Fertility and Sterility $\mathbf{8 1} 19-25$.

Guan G, Zhang D, Zheng Y, Wen L, Yu D, Lu Y \& Zhao Y 2014 microRNA423-3p promotes tumor progression via modulation of AdipoR2 in laryngeal carcinoma. International Journal of Clinical and Experimental Pathology 7 5683-5691.

Haouzi D, Assou S, Monzo C, Vincens C, Dechaud H \& Hamamah S 2012 Altered gene expression profile in cumulus cells of mature MII oocytes from patients with polycystic ovary syndrome. Human Reproduction 27 3523-3530. (doi:10.1093/humrep/des325)

Hatziapostolou M, Polytarchou C, Panutsopulos D, Covic L \& Tsichlis PN 2008 Proteinase-activated receptor-1-triggered activation of tumor progression locus-2 promotes actin cytoskeleton reorganization and cell migration. Cancer Research 68 1851-1861. (doi:10.1158/0008-5472. CAN-07-5793)

Hawkins SM \& Matzuk MM 2010 Oocyte-somatic cell communication and microRNA function in the ovary. Annales $d^{\prime}$ Endocrinologie 71 144-148. (doi:10.1016/j.ando.2010.02.020)

Hossain MM, Cao M, Wang Q, Kim JY, Schellander K, Tesfaye D \& Tsang BK 2013 Altered expression of miRNAs in a dihydrotestosterone-induced rat PCOS model. Journal of Ovarian Research 6 36. (doi:10.1186/17572215-6-36)

Huang X, Hao C, Shen X, Liu X, Shan Y, Zhang Y \& Chen L 2013a Differences in the transcriptional profiles of human cumulus cells isolated from $\mathrm{MI}$ and MII oocytes of patients with polycystic ovary syndrome. Reproduction 145 597-608.

Huang X, Hao C, Shen X, Zhang Y \& Liu X 2013b RUNX2, GPX3 and PTX3 gene expression profiling in cumulus cells are reflective oocyte/ embryo competence and potentially reliable predictors of embryo developmental competence in PCOS patients. Reproductive Biology and Endocrinology 11109.

Huang X, Hao C, Bao H, Wang M \& Dai H 2016 Aberrant expression of long noncoding RNAs in cumulus cells isolated from PCOS patients. Journal of Assisted Reproduction and Genetics 33 111-121. (doi:10.1007/ s10815-015-0630-z)

Jansen E, Laven JS, Dommerholt HB, Polman J, van Rijt C, van den Hurk C, Westland J, Mosselman S \& Fauser BC 2004 Abnormal gene expression profiles in human ovaries from polycystic ovary syndrome patients. Molecular Endocrinology 18 3050-3063. (doi:10.1210/ me.2004-0074)

Kandaraki E, Christakou C \& Diamanti-Kandarakis E 2009 Metabolic syndrome and polycystic ovary syndrome... and vice versa. Arquivos Brasileiros de Endocrinologia \& Metabologia 53 227-237.

Kenigsberg S, Bentov Y, Chalifa-Caspi V, Potashnik G, Ofir R \& Birk OS 2009 Gene expression microarray profiles of cumulus cells in lean and overweight-obese polycystic ovary syndrome patients. Molecular Human Reproduction 15 89-103.

Lin F, Li R, Pan ZX, Zhou B, Yu de B, Wang XG, Ma XS, Han J, Shen M \& Liu HL 2012 miRNA-26b promotes granulosa cell apoptosis by targeting ATM during follicular atresia in porcine ovary. PLOS ONE 7 e38640.
Liu S, Zhang X, Shi C, Lin J, Chen G, Wu B, Wu L, Shi H, Yuan Y, Zhou W et al. 2015 Altered microRNAs expression profiling in cumulus cells from patients with polycystic ovary syndrome. Journal of Translational Medicine 13238.

Livak KJ \& Schmittgen TD 2001 Analysis of relative gene expression data using real-time quantitative PCR and the 2(-Delta Delta C(T)) Method. Methods 25 402-408. (doi:10.1006/meth.2001.1262)

Manneras-Holm L, Benrick A \& Stener-Victorin E 2014 Gene expression in subcutaneous adipose tissue differs in women with polycystic ovary syndrome and controls matched pair-wise for age, body weight, and body mass index. Adipocyte 3 190-196. (doi:10.4161/adip.28731)

McCallie B, Schoolcraft WB \& Katz-Jaffe MG 2010 Aberration of blastocyst microRNA expression is associated with human infertility. Fertility and Sterility 93 2374-2382. (doi:10.1016/j.fertnstert.2009.01.069)

Mohamed-Hussein ZA \& Harun S 2009 Construction of a polycystic ovarian syndrome (PCOS) pathway based on the interactions of PCOSrelated proteins retrieved from bibliomic data. Theoretical Biology and Medical Modelling 6 18. (doi:10.1186/1742-4682-6-18)

Murri M, Insenser M, Fernandez-Duran E, San-Millan JL \& EscobarMorreale HF 2013 Effects of polycystic ovary syndrome (PCOS), sex hormones, and obesity on circulating miRNA-21, miRNA27b, miRNA-103, and miRNA-155 expression. Journal of Clinical Endocrinology and Metabolism 98 E1835-1844.

Nelson-Degrave VL, Wickenheisser JK, Hendricks KL, Asano T, Fujishiro M, Legro RS, Kimball SR, Strauss JF III \& McAllister JM 2005 Alterations in mitogen-activated protein kinase kinase and extracellular regulated kinase signaling in theca cells contribute to excessive androgen production in polycystic ovary syndrome. Molecular Endocrinology 19 379-390. (doi:10.1210/me.2004-0178)

Nishi Y, Yanase T, Mu Y, Oba K, Ichino I, Saito M, Nomura M, Mukasa C, Okabe T, Goto K et al. 2001 Establishment and characterization of a steroidogenic human granulosa-like tumor cell line, $\mathrm{KGN}$, that expresses functional follicle-stimulating hormone receptor. Endocrinology 142 437-445. (doi:10.1210/endo.142.1.7862)

Oksjoki S, Soderstrom M, Inki P, Vuorio E \& Anttila L 2005 Molecular profiling of polycystic ovaries for markers of cell invasion and matrix turnover. Fertility and Sterility 83 937-944. (doi:10.1016/j. fertnstert.2004.10.037)

Onalan G, Selam B, Baran Y, Cincik M, Onalan R, Gunduz U, Ural AU \& Pabuccu R 2005 Serum and follicular fluid levels of soluble Fas, soluble Fas ligand and apoptosis of luteinized granulosa cells in PCOS patients undergoing IVF. Human Reproduction 20 2391-2395. (doi:10.1093/ humrep/dei068)

Roth LW, McCallie B, Alvero R, Schoolcraft WB, Minjarez D \& KatzJaffe MG 2014 Altered microRNA and gene expression in the follicular fluid of women with polycystic ovary syndrome. Journal of Assisted Reproduction and Genetics 31 355-362. (doi:10.1007/s10815-0130161-4)

Seger R, Hanoch T, Rosenberg R, Dantes A, Merz WE, Strauss JF III \& Amsterdam A 2001 The ERK signaling cascade inhibits gonadotropinstimulated steroidogenesis. Journal of Biological Chemistry $\mathbf{2 7 6}$ 13957-13964.

Shi Y, Zhao H, Cao Y, Yang D, Li Z, Zhang B, Liang X, Li T, Chen J, Shen J et al. 2012 Genome-wide association study identifies eight new risk loci for polycystic ovary syndrome. Nature Genetics 44 1020-1025. (doi:10.1038/ng.2384)

Shi L, Liu S, Zhao W \& Shi J 2015 miRNA-483-5p and miRNA-486-5p are down-regulated in cumulus cells of metaphase II oocytes from women with polycystic ovary syndrome. Reproductive BioMedicine Online 31 565-572. (doi:10.1016/j.rbmo.2015.06.023)

Wang A, Lu C \& Qiao J 1998 [The effects of FSH,LH and insulin on steroids production by granulosa cells from polycystic ovaries syndrome]. Zhonghua Yi Xue Za Zhi 78 830-832.

Wickham EP III, Tao T, Nestler JE \& McGee EA 2013 Activation of the $\mathrm{LH}$ receptor up regulates the type 2 adiponectin receptor in human granulosa cells. Journal of Assisted Reproduction and Genetics 30 963-968. (doi:10.1007/s10815-013-0012-3)

Wild S, Pierpoint T, Jacobs H \& McKeigue P 2000 Long-term consequences of polycystic ovary syndrome: results of a 31 year follow-up study. Human Fertility 3 101-105. (doi:10.1080/1464727002000198781) 
Wood JR, Ho CK, Nelson-Degrave VL, McAllister JM \& Strauss JF III 2004 The molecular signature of polycystic ovary syndrome (PCOS) theca cells defined by gene expression profiling. Journal of Reproductive Immunology 63 51-60. (doi:10.1016/j.jri.2004.01.010)

Wood JR, Dumesic DA, Abbott DH \& Strauss JF III 2007 Molecular abnormalities in oocytes from women with polycystic ovary syndrome revealed by microarray analysis. Journal of Clinical Endocrinology and Metabolism 92 705-713. (doi:10.1210/jc.2006-2123)

Xu B, Zhang YW, Tong XH \& Liu YS 2015 Characterization of microRNA profile in human cumulus granulosa cells: identification of microRNAs that regulate Notch signaling and are associated with PCOS.
Molecular and Cellular Endocrinology 404 26-36. (doi:10.1016/j. mce.2015.01.030)

Yates LA, Norbury CJ \& Gilbert RJ 2013 The long and short of microRNA. Cell 153 516-519. (doi:10.1016/j.cell.2013.04.003)

Received 1 September 2015

First decision 1 October 2015

Revised manuscript received 13 March 2016

Accepted 21 March 2016 